\title{
Communicating research to practice: The role of professional association publications
}

\author{
Gaby Haddow
}

\begin{abstract}
Effective communication of research to practice should facilitate evidence based decision-making by library and information professionals. One way this may be achieved is through the publications distributed by library associations to their members. This paper reports on a study that explored the role of library associations' publications in communicating research information. Firstly, the reading habits of practitioners from a range of disciplines are discussed, finding support for making research information accessible through library associations' publications. Using content analysis, the extent and subject of research information published in two associations' publications were examined. Research information comprised a small proportion of the publications' content and much of the research information is presented as a brief mention only. The largest proportion of research information in both publications focuses on content about 'information behaviour, user needs/services'. The paper concludes by suggesting initiatives to improve practitioner access to research information in association publications.
\end{abstract}

\section{Introduction}

The philosophy behind evidence based practice is that important professional decision-making is undertaken after considering the best information available. It is generally held that the evidence most highly rated is research findings. For this to occur, access to research is critical, and access can relate to physical or cognitive factors. That is, relevant research must be available in sources that are routinely used and it must be discussed in language that is comprehensible to those who may benefit from it. This paper reports on a study which explored the first of these factors by examining the literature most frequently read by library

\section{Gaby Haddow}

Gaby Haddow teaches in the Department of Information Studies at Curtin University. Her $\mathrm{PhD}$ examined research communication, a focus continued in her professional and research interests.

Email: G.Haddow@ curtin.edu.au 
and information science (LIS) practitioners - the publications distributed by professional associations.

In the field of library and information science (LIS), research publication, reading and use has received a great deal of attention in the literature over many years. A number of concerns have been raised regarding the nature of LIS research, including that it is less scholarly and proportionally low compared to other disciplines (Fisher, 1999; Harvey, 2001; Peritz, 1981; Stephenson, 1990; Swigger, 1985). Others note a focus on pragmatic issues, rather than the development of theory from research (Montanelli and Mak, 1988; Robbins, 1990; Saracevic and Perk, 1973; Williamson, 1999), which has in turn led to the notion of a communication gap between research and practice (Blick, 1984; Clayton, 1992; Haddow and Klobas, 2004; Lynam, Slater, and Walker, 1982). In suggesting ways to close this communication gap, it is important to consider the time-poor and operations-focused environment in which LIS practitioners work (Clapton, 2010). Acknowledging the barriers to practitioners actually engaging in research, but encouraging practitioner reading of research, it has been proposed that researchers should report their findings in a way that is comprehensible to practitioners (Clayton, 1992; Turner, 2002; Waldhart, 1975). This may be achieved, for example, by reducing the amount of technical terminology used in research articles and including implications for practice (McKechnie, Julien, and Genuis, 2008). While the latter has been implemented by some journals, this strategy alone will not necessarily result in a journal being read by practitioners. It is the contention of this paper, and the motivation for the research on which it is based, that a pivotal issue in the communication of research to practice is the professional reading habits of practitioners.

\section{Professional reading by practitioners}

LIS practitioners share common characteristics with professionals in other fields in relation to their reading habits. Discussing the issue for practitioners in the information systems profession, Lang $(2002,871)$ notes the importance of selecting "suitable communication channels". Horder $(2004,304)$ provides a personal perspective as a social work practitioner and recalls: "Weekly trade publications ... were important in reducing a sense of isolation". The author also remarks on the limited access to libraries with journal collections and goes on to commend the Social Care Institute of Excellence for disseminating "summaries of knowledge for practice" (Horder, 2004, 307). In the field of recreation and leisure services, Jordan and Roland (1999) asked academics and practitioners about their reading habits. They found the most frequently read publications were practicebased (a larger proportion of practitioners than academics read these types of titles) and between $61-86 \%$ of the sample rarely or never read a research journal, citing lack of time as the primary barrier (Jordan and Roland, 1999, 170). Rudland and Kemp (2004) reviewed the literature about reading habits of teachers. Their results showed that $60 \%$ of a sample of K-5 (primary school) teachers never read research journals. Echoing Horder's comments, Rudland and Kemp note concerns relating to "the extent to which respondents have an ease of access to the professional reading material" (Rudland and Kemp, 2004, 12) and conclude with 
a suggestion to distribute "a gazette containing a variety of summaries and sources of recent and relevant publications" (Rudland and Kemp, 2004, 14).

These findings parallel those from previous work looking at research and practice in the LIS field. LIS practitioners tend to read and assign importance to publications other than scholarly journals (in which research is routinely reported). Blick (1984) and Robbins (1990) refer in general terms to the different reading habits of practitioners and researchers, and in Williams, McConnell and Wilson's (1997) study only a small proportion of the practitioners noted scholarly journals as an information source. More specifically, Ali $(1985,1986)$ found 'popular journals' were regularly scanned by practitioners, with the Library Association Record important for UK practitioners and American Libraries being the most frequently read title for US practitioners. This finding is repeated in studies by Tjourmas (1991) and Blake (1991), discussed by Rochester (1996). American Libraries was amongst the most important sources of information for the public library directors surveyed by Tjourmas and by the school library media coordinators in Blake's sample. Powell, Baker and Mika (2002) and Weaver (2002) report the same finding for American Libraries, with Weaver referring to two earlier lists, compiled in 1982 and 1999, which also included this title as the most important publication for practitioners. In her conclusion, Weaver suggests that since most of the librarians surveyed browse their reading material and report lack of time as a barrier to reading, a solution may be to publish "concise and accurate abstracts to articles" (Weaver, 2002, 5).

Similar findings have been found in studies of LIS practitioner reading habits in Australia and for German-language countries. Haddow's (2001) doctoral research found $80 \%$ of a small sample of Australian library practitioners reported reading newsletter-types of publications, compared with $62 \%$ who read scholarly journals. The most frequently read title was inCite, the newsletter distributed to members of the Australian Library and Information Association (ALIA). Schlogl and Stock (2008) conducted a reader survey of practitioners in German-language countries, finding Bibliotheksdienst the most frequently mentioned title. inCite, like American Libraries and the Library Association Record (now Library + Information Update) are distributed freely as part of the respective association's membership entitlements. Bibliotheksdienst is subject to a subscription fee which is cheaper for members than non-members of the German professional association. With the exception of American Libraries (published bimonthly), the titles are monthly publications.

The literature clearly indicates that the publications of library associations reach a wider practitioner audience than any of the scholarly titles in the LIS field. And it follows that they are potentially the most useful medium for the communication of research information. Moreover, it is the professional associations responsible for these publications that encourage, and are the primary sources of, professional development activities for their members. There is clearly an opportunity for professional association publications to play a major role in developing an evidence base for their practitioner members. The small study undertaken and reported here aimed to determine whether this role was evident in the content of two of these publications. 


\section{Methods}

A content analysis of two professional association publications, both distributed freely to members on a monthly basis, was conducted to identify the extent and subject of research information included in the publications over the period of one year, 2008. Described as magazines, the publications examined were Library + Information Update (Update), from the Chartered Institute of Library and Information Professionals (CILIP) and inCite, from the Australian Library and Information Association (ALIA).

The content was examined by the author, using print copies of all issues published in 2008. An initial scan of the publications led to determining exclusions from the content for analysis. These were: calls for papers; conference announcements; events and activities notices; book reviews; and advertisements. The 'Media watch' column in Update was also excluded. As well as short pieces and articles, editorials, letters to the editor, obituaries and current awareness columns (for example, useful websites) were included for examination of research content. Each issue was read closely and research content was noted in a table developed for the study. A second examination of the issues was then conducted to ensure all relevant content had been identified and to check that categorization of content had been carried out consistently.

Two aspects of research content were coded for analysis. Firstly, the extent of information about research and secondly, the subject matter of the research. Extent of research content was identified as belonging to one of three categories, determined from the first close reading. These were:

- Brief mention - for example, a sentence noting a research report had been published or a reference to a study without further discussion.

- Substantive mention - for example, when the aims, very brief study findings, and/or research method were discussed.

- Expanded discussion - for example, an entire article reporting on a research project or providing extensive information about research design and findings.

Summary details of each instance of research content were noted. In some cases it was difficult to draw clear distinctions between the different categories for extent and as a result the coding tended to the generous. To provide comparative results for the publications, the extent of research content was calculated as a ratio (presented as a percentage) of the total pages published in the publication for 2008.

In most cases it was impossible to determine subject with any degree of certainty from the brief mentions of research, and by their nature these instances of research content do not provide information with which practitioners can make informed decisions. Therefore, only the substantive mention and expanded discussion categories of research content were analysed for subject. The categories for subject of research content were drawn directly from the content, resulting in a wide range of subjects being noted in the first examination. However, on second reading of the content a number of the subjects were so closely related and potentially indistinguishable that the original categories were merged. For 
example, content about a survey of users to determine their resource needs was considered to be a component of the subject area of information behaviour, even though the terminology differed. Similarly, content relating to a survey of new graduates was deemed closely linked to content discussing the skills required by LIS practitioners.

\section{Results}

\subsection{Extent of research content}

In 2008, the issues in Update comprised a total of 510 pages and inCite published 418 pages. For both publications, the mentions of research in the brief and substantive categories greatly exceed the extent of research content in the expanded discussion category. The total research content of Update is almost double that of inCite, with a similar result when comparing research content in the expanded discussion category. These findings are presented in Table 1 below.

\begin{tabular}{|lllllllll|}
\hline & & & Brief mention & \multicolumn{2}{l}{$\begin{array}{l}\text { Substantive } \\
\text { mention }\end{array}$} & $\begin{array}{l}\text { Expanded } \\
\text { discussion }\end{array}$ & \multicolumn{2}{l}{$\begin{array}{l}\text { Total } \\
\text { research } \\
\text { content }\end{array}$} \\
\hline & No. & $\mathrm{R}(\%)^{*}$ & No. & $\mathrm{R}(\%)$ & No. & $\mathrm{R}(\%)$ & No. & $\mathrm{R}(\%)$ \\
\cline { 2 - 9 } Update & 39 & 7.6 & 34 & 6.7 & 9 & 1.8 & 82 & 16 \\
inCite & 17 & 4.0 & 18 & 4.3 & 3 & 0.7 & 38 & 9 \\
*R (ratio) calculated as a percentage: number of content category instances to \\
total number of pages published
\end{tabular}

Table 1: Extent of research content in Update and inCite

\subsection{Subject of research content}

A total of nine subject categories were determined after the second reading of the publications' content. They are listed below in Table 2. Given the small numbers involved in this analysis, ratios were not calculated. Instead, only the raw numbers are reported alongside each subject category.

The findings indicate there are subjects common to both publications that are more frequently discussed in their content. Two of the subjects, the 'information behaviour' and 'LIS profession' categories, were the product of merging categories at the time of the second examination. A major difference between the publications' research content can be seen in the management subject category, with Update carrying almost four times the content as inCite (based on a percentage of the two categories of research extent). 'External policy' research content is also higher in Update. This subject encompassed discussion such as copyright, knowledge economy, and government reviews. There is the potential for merging the categories 'collection management' and 'digital/digitizing collections', although the content tended to focus on the quite different aspects reflected in the category titles. Looking more closely at this research content it was found that e-books were discussed in only two instances, both in Update. 'Information technology' was used to code content that discussed library 
management systems. While it might be expected that this subject would be the focus of more LIS research information, the content examined indicated that information technology was most often discussed in connection with one of the other subject categories. For example, content relating to technology skills of librarians was coded with the LIS profession category.

\begin{tabular}{|c|c|c|c|c|}
\hline & \multicolumn{2}{|c|}{ Update } & \multicolumn{2}{|c|}{ inCite } \\
\hline & $\begin{array}{c}\text { Substantive } \\
\text { mention }\end{array}$ & $\begin{array}{l}\text { Expanded } \\
\text { discussion }\end{array}$ & $\begin{array}{l}\text { Substantive } \\
\text { mention }\end{array}$ & $\begin{array}{l}\text { Expanded } \\
\text { discussion }\end{array}$ \\
\hline $\begin{array}{l}\text { Information behaviour, } \\
\text { user needs/services }\end{array}$ & 9 & 2 & 5 & 2 \\
\hline Management & 8 & & 1 & \\
\hline LIS profession & 6 & 2 & 7 & \\
\hline External policy & 4 & & 1 & \\
\hline $\begin{array}{l}\text { Collection } \\
\text { management }\end{array}$ & 3 & 1 & 1 & \\
\hline $\begin{array}{l}\text { Digital/digitizing } \\
\text { collections }\end{array}$ & 2 & 1 & 1 & 1 \\
\hline $\begin{array}{l}\text { Community } \\
\text { engagement }\end{array}$ & 1 & & 1 & \\
\hline Information literacy & 1 & 2 & 1 & \\
\hline $\begin{array}{l}\text { Information } \\
\text { technology }\end{array}$ & & 1 & & \\
\hline Total & 34 & 9 & 18 & 3 \\
\hline
\end{tabular}

Table 2: Subject of research content in Update and inCite (substantive mention and expanded discussion categories only)

\section{Discussion}

As an important source of professional reading material, the associations' publications have the potential to communicate research information to practitioners. Based on the findings of this study, this potential is not being realized. Research information comprises only a small proportion of the publications' content. Update, with $16 \%$ research content, includes almost twice the amount of research content as inCite, with $9 \%$. However, nearly half of the research content in both publications was in the form of brief mentions of research. This content provides no real guidance for readers as it is typically a sentence, or two at most, referring to a project or publication or espousing the value of research. For both publications, the mentions of research in the brief and substantive categories greatly exceed the extent of research content in the expanded discussion category. The expanded discussions of research, of which there were few, were excellent and clearly targeted at a practitioner audience. 
It is interesting to note which subjects of research are being published in Update and inCite; indicative perhaps of the importance placed on different aspects of the LIS profession. The most frequently discussed subject in both publications is 'information behaviour, user needs/services', core functions and foci for information services of all types. With the equal highest content of expanded discussion, albeit two instances in each publication, these pieces could provide valuable research information for practitioners. The findings are not dissimilar to the trends discussed by Rochester and Vakkari (2003) in which 'library and information services' was the most frequently published research topic in UK and Australian journals of LIS.

Another subject frequently discussed in both publications is the LIS profession. Although this topic is noted in previous content analyses of LIS journals (Rochester and Vakkari, 2003), it is not amongst the most frequently researched topics. The findings of this study beg the question; why is research information about the LIS profession published in such a relatively high proportion in the associations' publications? In terms of usefulness to practitioners, this research area would seem to be of limited relevance.

A marked difference between the research content of Update and inCite is in the extent of information published about management issues. Update, with four times the instances of research information on management topics than inCite, appears to be continuing a trend found by a 1998 study (Layzell Ward, reviewed by Rochester and Vakkari, 2003). This study found that 'administration and planning' became the most frequently researched topic in UK research literature in 1985 and again in 1995. The low proportion of research information about management in inCite suggests that a comment by Whyte in 1976 that library management is a "non-preoccupation of Australian librarians" (Whyte, 1976, 211) may hold true three decades later.

Comparatively little research information was published about 'digital/digitizing collections', a subject which is challenging many library services today. Also, 'information literacy', one of the most widely researched aspects of LIS, is rarely discussed in the associations' publications.

These comments should be considered as tentative conclusions only due to the range of factors likely to influence the content of the associations' publications. For example, copy for the publications may be just as much a product of the editors' focus as the motivation of authors submitting pieces for publication. Decisions on research content may also relate to the scholarly journals access provided by the associations. Members of CILIP and ALIA are entitled to free access to the LISA database and the ProQuest LIS journal subset, respectively. If members are accessing these sources of research information (the associations were contacted to request access data but were unable to provide it), then there is some logic to publishing content that is primarily current awareness pieces in the Update and inCite publications.

However, a decision to remain removed from the research communication process does not address the findings for practitioner reading habits and does not take into account the many frameworks available to improve the communication of research to practice. A systematic review on dissemination of research findings 
(Wilson, Petticrew, Calnan and Nazareth, 2010) argues that theoretical frameworks are a useful tool for considering in research communication. One of these is based on the Persuasive Communication Matrix and includes:

...five variables that influence the impact of persuasive communications. These are the source of communication, the message to be communicated, the channels of communication, the characteristics of the audience (receiver), and the setting (destination) in which the communication is received.

(Wilson et al., 2010, para 22)

It is argued here that for effective communication of research information in LIS it is important to take note of previous research on practitioner reading habits, the best available evidence, and ensure that practitioners have the opportunity to read research information in the sources and through the channels that they are most likely to access. An interesting question arises from the recent move by both associations to deliver their publication, at least partly, online - that is, will the different communication channel affect practitioner reading habits and therefore demand reconsideration of the most effective means of communicating research to practice.

\section{Limitations in the study}

There are two important limitations that should be acknowledged in relation to this study in particular, and to content analysis as a methodology more generally. Firstly, the scale of the study is small and although a year's issues constitute extensive material to analyse, the results may be more representative if a longer publishing period was sampled. In addition, the restriction to two professional associations' publications for examination means that the results are limited to UK and Australian contexts only. American Libraries, as the publication noted in several studies about practitioner reading habits, would be the logical addition to the sample in any future study of the same type.

Secondly, and related to the research method applied, more than one coder for analyzing content is recommended. Content analysis is a time-consuming and exacting method, and a sole coder frequently experiences self-doubt and concerns about consistency.

While the aim of this study was limited to examining the content of the associations' publications, it would be useful to consider alternative sources of professional reading in future. The availability of blogs, wikis and other websites could be an important source of research information and a source that can be accessed when required; an important factor for practitioners who may turn to research when in need rather than habitually read research information.

\section{Conclusion and implications for practice}

It is important to appreciate the implications of failing to address, in a serious and sustained manner, the communication of research to practitioners. Library services are not under the same pressure as the health industry, for instance, where evidence based practice has a resonation that professionals and clients can relate to. As Cullen (cited by Powell, Baker \& Mika, 2002, 51) comments, there are "no 
matters of life and death" to motivate higher use of research by LIS practitioners. However, there is abundant professional literature to suggest that evaluating services and accountability to parent organisations and funders is an increasingly significant aspect of a practitioner's role, with both governments and library organisations involved (see for example, Department for Culture Media and Sport (2010) and Library Council of New South Wales (2008)). To meet these demands library practitioners will need to incorporate the best possible evidence into their decision-making and provide reliable evidence to their managers. Ideally, this evidence should be drawn from systematic data collection in their own context, based on proven data collection methods drawn from previous research. Without access to this information, practitioners face the prospect of developing (and possibly re-inventing) projects on an individual basis.

Previous studies indicate that the publications of library associations are read by more practitioners than any other title in the LIS literature and their potential as the most useful channel for communicating research information is important to harness. By including research information in these publications two barriers to research communication are addressed. Firstly, because the publications are received as a membership entitlement the physical access barrier is overcome. Secondly, authors writing about research for these publications presumably consider their reader audience and therefore deliver the information in a style that is appropriate, thereby addressing the cognitive barriers to accessing research information.

Library associations should consider including more research information in the form of substantive or expanded discussion in their publications. This is not a new or novel suggestion. In an editorial in 1999, Schwartz and Hernon note that a committee of the American Association of School Librarians was responsible for "preparing summaries of research of interest to the school library media community" (Schwartz and Hernon, 1999, 143). Currently, research summaries are included in the open access journal Evidence Based Library \& Information Practice, with similar information about management research available online (at http://www.evidence-basedmanagement.com/). These are ready made sources that could be adapted for the associations' publications. In addition, requests for short pieces could be made to researchers working in areas with relevance to practitioners, ensuring that useful research content is included in the publications. Strategies that have been adopted in other fields might be effective, such as the regular publication of a two page article that discusses the latest evidence available on a specific topic in the newsletter publication of the Royal College of Nursing Australia.

In conclusion, there is a role for library associations to make research information more widely available to LIS practitioners through the publications that are most frequently read by them. This study shows that the research information content of these publications is relatively low and generally presented as a brief mention only. Substantial and expanded discussions of research in the publications provide both physical and cognitive access to research information, and it is from these that practitioners and their services will derive the greatest benefit. 


\section{References}

Ali, S. N. (1985) Library science research: some results of its dissemination and utilization, Libri 35(2), 151-162.

Ali, S. N. (1986) Attitudes and preferences of library practitioners in Illinois to channels for dissemination of research results, College and Research Libraries, 47(2), 167-172.

Blick, A. R. (1984) Information science research versus the practitioner. In: Dietschmann, H. J. (ed.) Representation and exchange of knowledge as a basis of information processes. Amsterdam: North-Holland. 231-244.

Clapton, J. (2010) Library and information science practitioners writing for publication: Motivations, barriers and supports, Library and Information Research, 34(106), 7-21.

Clayton, P. 1992. Bridging the gap: Research and practice in librarianship. In: Clayton, P. and McCaskie, R. (eds.) Priorities for the Future: Proceedings of the First National Reference and Information Service Section Conference and the University, College and Research Libraries Section Workshop on Research. Canberra, ACT: D. W. Thorpe. 73-76.

Department for Culture, Media and Sport (2010) The modernisation review of public libraries: a policy statement. URL:

http://webarchive.nationalarchives.gov.uk/+/http://www.culture.gov.uk/images/co nsultation_responses/modernisation_review_public_libraries.pdf [accessed 16.11.10].

Fisher, W. (1999) When write is wrong: is all our professional literature on the same page? Library Collections, Acquisitions, and Technical Services, 23(1), 6172 .

Haddow, G. (2001) The diffusion of information retrieval research within librarianship: A communication framework. PhD dissertation, University of Western Australia.

Haddow, G. and Klobas, J. E. (2004) Communication of research to practice in library and information science: Closing the gap, Library \& Information Science Research, 26(1), 29-43.

Harvey, R. (2001) Losing the quality battle in Australian education for librarianship, Australian Library Journal 50(1), 15-22.

Horder, W. (2004) Reading and not reading in professional practice, Qualitative Social Work, 3(3), 297-311.

Jordan, D.J. and Roland, M. (1999) An examination of differences between academics and practitioners in frequency of reading research and attitudes toward research, Journal of Leisure Research, 31(2), 166-170.

Lang, M. (2002) On the dissemination of I.S. research findings into practice. Proceedings of the Informing Science + IT Education Conference, Cork. URL: http://informingscience.org/proceedings/IS2002Proceedings/papers/Lang102OnT he.pdf [accessed 16.11.10]. 
Library Council of New South Wales (2008) Enriching communities: the value of public libraries in New South Wales. Sydney, NSW: Library Council of New South Wales. URL:

http://www.sl.nsw.gov.au/services/public_libraries/publications/docs/enriching_c ommunities.pdf [accessed 16.11.10].

Lynam, P., Slater, M. and Walker, R. (1982) Research and the practitioner: dissemination of research results within the library-information profession, Aslib Occaional Publication. London: Aslib.

McKechnie, L., Julien, H. and Genuis, S. K. (2008) Communicating research findings to library and information science practitioners: A study of ISIC papers from 1996 to 2000, Information Research [online], 13(4). URL: http://informationr.net/ir/13-4/paper375.html [accessed 15.01.11].

Montanelli, D. S. and Mak, C. (1988) Library practitioners' use of library literature. Library Trends, 36(Spring), 765-783.

Peritz, B. C. (1981) Citation characteristics in library science: Some further results from a bibliometric survey, Library Research, 3, 47-65.

Powell, R. R., Baker, L. M. and Mika, J. J. (2002) Library and information science practitioners and research, Library and Information Science Research, 24, 49-72.

Robbins, J. B. (1990) Research in information service practice, Library and Information Science Research, 12, 127-129.

Rochester, M. (1996) Professional communication through journal articles, Australian Academic \& Research Libraries, 27(3), 191-199.

Rochester, M. and Vakkari, P. (2003) International library and information science research: a comparison of national trends, IFLA Professional Reports, No. 82. URL: http://archive.ifla.org/VII/s24/pub/iflapr-82-e.pdf [accessed 16.11.10).

Rudland, N. and Kemp, C. (2004) The professional reading habits of teachers: Implications for student learning, Australasian Journal of Special Education 28(1), 4-17.

Saracevic, T. and Perk, L. J. (1973) Ascertaining activities in a subject area through bibliometric analysis, Journal of the American Society for Information Science, 24, 120-134.

Schlogl, C. and Stock, W. G. (2008) Practitioners and academics as authors and readers: the case of LIS journals, Journal of Documentation, 64(5), 643-666.

Schwartz, C. and Hernon, P. (1999) Professional associations and LIS research, Library \& Information Science Research, 21(2), 141-151.

Stephenson, M. S. (1990) Teaching research methods in library and information studies programs, Journal of Education for Library and Information Science, 31(1), 49-66.

Swigger, K. (1985) Institutional affiliations of authors of research articles, Journal of Education for Library and Information Science, 26, 105-109. 
Turner, K. J. (2002) Do information professionals use research published in LIS journals? 68th IFLA Council and General Conference, Glasgow. URL: http://archive.ifla.org/IV/ifla68/papers/009-118e.pdf [accessed 16.11.10].

Waldhart, T. J. (1975) The impact of research on professional practice: a proposed communication innovation. Information Revolution: Proceedings of the 38th ASIS Annual Meeting, 12, 26-27.

Weaver, S. M. (2002) The professional reading habits of American librarians, 68th IFLA Council and General Conference. Glasgow. URL:

http://archive.ifla.org/IV/ifla68/papers/166-118e.pdf [accessed 16.11.10].

Whyte, J. P. (1976) Issues in Australian librarianship: an examination of the Australian Library Journal and the Proceedings of the Conferences of the Library Association of Australia, 1951-1972. In: Rayward, W.B. (ed.) The variety of librarianship: Essays in honour of John Wallace Metcalfe. Sydney: Library Association of Australia. 190-217.

Williams, D., McConnell, M. and Wilson K. (1997) Is there any knowledge out there? The impact of research information on practitioners. British Library Research and Innovation Report 62. London: British Library.

Williamson, K. (1999) The role of research in professional practice: with reference to the assessment of the information and library needs of older people, Australasian Public Libraries and Information Services, 12(4), 145-153.

Wilson, P.M., Petticrew, M., Calnan, M.W. and Nazareth, I. (2010) Disseminating research findings: what should researchers do? A systematic scoping review of conceptual frameworks, Implementation Science, 5(91). URL:

http://www.implementationscience.com/content/5/1/91 [accessed 21.12.10].

\section{Open access and copyright}

Library and Information Research is an open access journal. A freely available copy of this paper may be downloaded from the journal's website:

http://www.cilipjournals.org.uk/lir

Copyright and associated moral rights in works published in Library and Information Research are retained by the author(s) but this paper may be used freely, with proper attribution, in educational and other non-commercial settings. 